\title{
Effect of size reduction on colour, hydration and rheological properties of wheat bran
}

\author{
Oluwatoyin Oladayo ONIPE ${ }^{1}$, Daniso BESWA², Afam Israel Obiefuna JIDEANI ${ }^{1 \star}$
}

\begin{abstract}
The aim of this study was to determine the effect of size reduction of wheat bran (WB) on water holding capacity (WHC), water retention capacity (WRC), swelling capacity (SC); rheological and colour properties. Coarse WB exhibited the highest mean values for WHC $(6.49 \mathrm{~g} / \mathrm{g})$, WRC $(5.76 \mathrm{~g} / \mathrm{g})$, SC $(7.67 \mathrm{~g} / \mathrm{g})$ and OHC $(4.23 \mathrm{~g} / \mathrm{g})$, while these values were significantly reduced in fine WB. Size reduction increased lightness of WB as indicated by high $\mathrm{L}^{\star}$ values (62.65 to 75.80 ), Hue angle of 74.63 and whiteness index value of 81.42 . Increasing WB additions increased water absorption of dough from 63 to $70.2 \%$, while dough stability decreased from $12.5 \mathrm{~min}$ to $6.80 \mathrm{~min}$. As coarse WB addition increased from 1 to $15 \mathrm{~g}$ extensibility decreased from $419 \mathrm{BU}$ to $283 \mathrm{BU}$ (highest level of addition). A negative correlation $\left(\mathrm{r}^{2}=-0.992\right)$ was found between farinograph water absorption and all extensograph indices measured; implying that an increase in water absorption of dough led to a significant decrease in extensibility, maximum resistance and energy recorded for the dough. WB can be used as potential additive in foods like bread/ doughnut with the aim of optimizing their quality parameters such as nutritional and textural properties.
\end{abstract}

Keywords: wheat bran; rheology; colour profile; hydration properties; mixing tolerance; particle size.

Practical Application: Impact of size reduction of wheat bran on colour and rheological attributes is potentially applicable in development of existing and new cereal products.

\section{Introduction}

Wheat bran (WB) is an essential by-product of wheat during the milling process, and contains about $45-53 \%$ dietary fibre (Majzoobi et al., 2012; Onipe et al., 2015). Several health benefits have been accrued to consumption of WB-enriched or whole wheat foods such as improved gut health, reduced risk of colon cancer and cardiovascular diseases; and these benefits are linked to minerals, vitamins and other phytochemicals that are present in the bran fraction of wheat (Onipe et al., 2015). Although WB has mainly been used as animal feed supplements its use as human food is still less than expected because of its unfavourable impact on functional and sensory properties (Kock et al., 1999; Zhang \& Moore, 1999; Song et al., 2013; Hemdane et al., 2015). Partial substitution of wheat flour with WB has been associated with low loaf volume (Noort et al., 2010; Gómez et al., 2011), less desirable organoleptic properties (Yadav \& Rajan, 2012), and increased hardness of food (Sobota et al., 2015). The negative effect of WB addition on bread has been attributed to a number of factors including dilution of gluten proteins, although this factor is also dependent on the gluten quality of the flour being used (Noort et al., 2010; Hemdane et al., 2015). Size reduction changes the structure of WB, thereby altering the physical, chemical and functional properties of the WB (Zhu et al., 2011). WB is known for its significant water absorption due to high content of polysaccharides which are known to bind water through the formation of hydrogen bonds. However, the mechanism behind water absorption varies with the particle size of WB whether it is on a macro, micro or nano scale. Due to the large pore size of coarse WB and the effect of stacking, it retains more water in its tissue layer spaces and empty pericarp cells (Chesson et al., 1997). Functionality of WB can also be traced to the wheat cultivar from which it was extracted. Addition of WB to bread has an effect on its colour. Majzoobi et al. (2012) reports that in addition to Maillard reaction, the crust colour of bread darkened as the particles size and addition level of WB increased.

When wheat flour is hydrated, the dough forms a viscoelastic system in which gluten proteins surround the starch granules to form the dough structure (Zaidel et al., 2010; Hadnađev et al., 2011). In cereal science, rheological measurements are recognized as a vital tool in assessing the baking quality of flour. These measurements are used throughout the whole processing chain to help keep a track of molecular structure, mechanical properties, mixing and extensional properties in order to know what to expect of the quality of the final product (Dobraszczyk \& Morgenstern, 2003). Functionality of bran in bread or pastry products is usually evaluated by dough or bread characteristics. Addition of bran fractions to wheat flour often brings about detrimental effects on dough properties with regards to fermentation, gas retention, bread-loaf volume, dough texture and consistency (Zhang \& Moore, 1999). It is also important to know that the functionality of bran in dough is also to an extent determined by the quality and/or strength of flour used and the cultivar origin of the flour and/ or bran used (Hemdane et al., 2016). Behavioural features of WB and other dietary fibres during mixing using farinograph and extensograph measurement 
has been extensively studied and reviewed (Wang et al., 2002; Hadnađev et al., 2011; Miś et al., 2012; Ahmed et al., 2013) With low consumer acceptability of WB-enriched products, size reduction can be adopted with the aim of reducing the grittiness and appearance of WB in food products. The objective of this study is to evaluate the effect of size reduction on hydration, rheological and colour properties of WB.

\section{Materials and methods}

\subsection{Sample preparation}

Commercial wheat bran (WB) and white bread wheat flour (Premier Foods/Mills, South Africa) were purchased from a local supermarket and milled using ultra-centrifugal mill (Retsch ZM 200, Haan Germany). Milled bran was sieved using vibratory sieve shaker (Fritsch Analysette 3 SPARTAN, Idar-Oberstein Germany) to get medium and fine particle sizes. WB was stored in airtight polyethylene bags of $0.38 \mathrm{~mm}$ thickness and stored at $-20{ }^{\circ} \mathrm{C}$ for further analysis.

\subsection{Hydration properties}

\section{Water retention capacity (WRC)}

The WRC of WB was determined following AACC method 56-11.02 (American Association of Cereal Chemists, 2000). A $15 \mathrm{~mL}$ graduated centrifuge tube with screw cap was weighed. WRC was calculated using Equation 1

$$
\text { WRC }(g / g)=\frac{\text { Residue weight after centrifugation }- \text { Residue dry weight }}{\text { Residue dry weight }}
$$

\section{Water holding capacity (WHC)}

Water holding capacity is defined as water held by one gram of bran fibre without application of an external force. The WHC of WB was measured following the method of Raghavendra et al. (2004) with slight modifications. Approximately $1 \mathrm{~g}$ of dry bran sample was weighed into a $50 \mathrm{~mL}$ graduated test tube. Around $30 \mathrm{~mL}$ of deionised water was added and it was hydrated for $18 \mathrm{~h}$ at ambient temperature. Supernatant was filtrated off on a paper towel. Hydrated residue was weighed and then dried at $105^{\circ} \mathrm{C}$ for $2 \mathrm{~h}$. WHC and calculated using Equation 2

WHC $(g / g)=\frac{\text { Residue hydrated weight }- \text { Residue dry weight }}{\text { Residue dry weight }}$

\section{Swelling capacity}

Swelling property of WB was determined as described by Raghavendra et al. (2004) In a $15 \mathrm{~mL}$ graduated test tube, $10 \mathrm{~mL}$ deionised water, was added to $0.2 \mathrm{~g}$ of WB and allowed to hydrate for $18 \mathrm{~h}$. Volume attained by WB was measured. SC was calculated using the Equation 3

$\mathrm{SC}(\mathrm{mL} / \mathrm{g})=\frac{\text { Volume occupied by sample }}{\text { Original sample weight }}$

\subsection{Bulk and packed density}

Bulk and packed density of WB was determined according to the method described by Prakongpan et al. (2002).

Bulk density

A clean, dry $50 \mathrm{~mL}$ graduated measuring cylinder was weighed. It was filled with $\mathrm{WB}$ and shaken slightly and the volume was recorded. The weight of the cylinder and content was measured. Bulk density was calculated using the Equation 4

Bulk density $(\mathrm{g} / \mathrm{mL})=\frac{\text { Sample weight }}{\text { Sample volume }}$

\section{Packed density}

A clean, dry $10 \mathrm{~mL}$ measuring cylinder was filled with $2 \mathrm{~g}$ of WB. Cylinder was manually tapped until there was no further reduction in volume. The packed volume was recorded. Packed density was calculated using the Equation 5

Packed density $(\mathrm{g} / \mathrm{mL})=\frac{\text { Sample weight }}{\text { Packed volume }}$

\subsection{Colour properties}

Colour attributes of WB was determined using a Colourflex spectrophotometer (Hunter Associates Laboratory, Reston, Va., U.S.A). Hunter values $L^{\star} a^{\star}$ and $b^{\star}$ values were determined. $\mathrm{L}^{\star}$ measures lightness from black to white (0-100); $\mathrm{a}^{\star}$ indicates red $(+)$ to green $(-)$; while $b^{\star}$ measures yellow $(+)$ to blue $(-)$. Hue, Chroma, whiteness and yellowness index were calculated from $L^{\star} a^{\star} b^{\star}$ values obtained from WB samples (Equations 6-9).

$$
\operatorname{Hue}\left(\mathrm{H}^{\circ}\right)=\tan ^{-1}\left\{\frac{\mathrm{b}^{*}}{\mathrm{a}^{*}}\right\}
$$

$$
\text { Chroma }=\sqrt{\left(a^{*}\right)^{2}+\left(a^{*}\right)^{2}}
$$

Whiteness index $=100-\sqrt{\left(100-\mathrm{L}^{*}\right)+\mathrm{a}^{*^{2}+\mathrm{b}^{2}}}$

Yellowness index $=\frac{142.86 \mathrm{~b}^{*}}{\mathrm{~L}^{*}}$

\subsection{Rheological properties}

Wheat flour-WB blend was made using ratios 99:1, 92:8 and $85: 15$. The blends were subjected to rheology tests.

\section{Farinograph test}

Behaviour of the wheat flour-WB blends during mixing and dough development were determined by a Brabender Farinograph-E (model 810112 Duisburg Germany), using AACC method 54-21.02 (American Association of Cereal Chemists, 2000) based on constant flour weight. 


\section{Extensograph measurement}

The extensibility properties of dough were measured using a Brabender Extensograph-E (model 860703, Duisburg Germany). Measurement was carried out using AACC method 15.10.01 American Association of Cereal Chemists (2000) Dough used for the test was prepared from $300 \mathrm{~g}$ flour (14\% moisture), $6 \mathrm{~g}$ salt and water (Farinograph water absorption value). Proving time for the test was $45 \mathrm{~min}$.

\subsection{Statistical analysis}

Results were presented as mean values \pm standard deviation (SD) of three replications. Statistical analysis was conducted using the one-way analysis of variance (ANOVA) and means of results for each experiment compared, using the Duncan multiple comparison test $\mathrm{p}<0.05$ confidence levels. Pearson's correlation was used to determine the relationship between farinograph and extensograph indices according to Miś et al. (2012). SPSS 23 for windows (SPSS Inc., Chicago, IL) statistical software package was used for all statistical analysis.

\section{Results and discussion}

\subsection{Hydration properties}

Size reduction had significant effect on water-holding capacity (WHC), water-retention capacity (WRC) and swelling capacity (SC) of WB as shown below (Figure 1) WHC, WRC and SC ranged from 3.39-6.49, 2.17-5.76 and 3.50-7.67 respectively. All hydration properties decreased significantly $(\mathrm{p}<0.05)$ as the particle size of WB was reduced, with the exception of WHC of

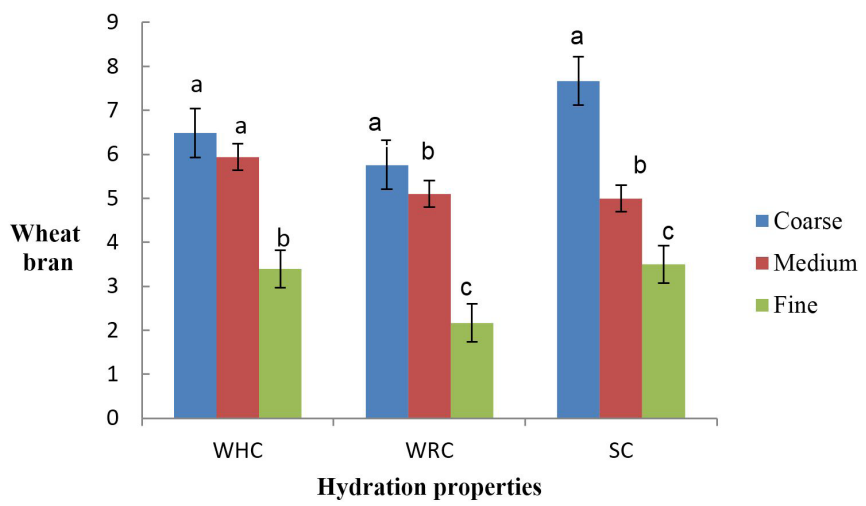

Figure 1. Effect of size reduction on hydration properties of wheat bran. Results are means of three replicates. Bars with different super script letters denote hydration properties which significantly differ $(\mathrm{p}<0.05)$ from each other. coarse WB and medium WB which did not differ significantly. These results are in close agreement with the values recorded by other authors (Table 1); and indicate that factors such as differences in methodology and fibre type are to be considered when making this comparison. Zhu et al. (2011) reports that WHC of WB of ultra-particle size $(0.1-1 \mu \mathrm{m})$ reduced from 5.89 to $3.45 \mathrm{~g} / \mathrm{g}$.

The high hydration mean values of coarse WB can be linked to the interspatial void between the fibres and the large pore sizes in the fibre pericarp (Hemdane et al., 2016). Size reduction changes the structure of WB fibre, which in turn impacts directly on the hydration properties. Due to its high affinity for water, WB fibre pores are filled with water when hydrated. Low hydration mean values for fine WB can be linked to alteration of the porous matrix structure which reduces the pore sizes, and in turn reduces the amount of water held in the pores (Zhu et al., 2011).

In a recent study, hydration properties of a wider range of WB particle sizes $(77-1687 \mu \mathrm{m})$ were used. WRC and WHC values obtained for $1687 \mu \mathrm{m}$ WB size are still similar to the values for coarse WB in our study (Jacobs et al., 2015). It has been reported that the reduction of WHC in fine WB is caused by a reduction in direct absorption or reduced capillary forces (Noort et al., 2010). These authors also developed a different technique for measurement of WRC and the values obtained from this new method were quite lower than the traditional centrifugation method. Swelling capacity values in their study were higher than the ones recorded in our study also because of a difference in methodology. Bulk and packed density of WB ranged from 0.17 to 0.32 and 0.21 to 0.42 (Table 2 ) respectively. Results revealed that as particle size reduced, bulk and packed density of WB significantly increased $(\mathrm{p}<0.05)$. In a previous study, an increase of 0.14 to $0.17 \mathrm{~g} / \mathrm{mL}$ was recorded for bulk density with decrease in pineapple dietary fibre size from $>170$ to 100 mesh size (Prakongpan et al., 2002).Bulk density of a particulate substance is dependent on the density of particles and spatial arrangement of particles in the substance (Prakongpan et al., 2002). For example, $1 \mathrm{~g}$ of coarse WB in a test tube had more interspatial void volume because of its bigger particle size while $1 \mathrm{~g}$ of fine WB occupied less space because of the finer particle size. This justifies the definition of bulk density as ratio of untapped sample mass and its volume alongside the contribution of interspatial void volume.

\subsection{Density of wheat bran}

Contrary to the results in this study, an earlier study reported bulk densities of $5.20 \mathrm{~g} / \mathrm{mL}, 8.20 \mathrm{~g} / \mathrm{mL} \& 16.80 \mathrm{~g} / \mathrm{mL}$ for fine, medium and coarse bran, respectively (Prakash, 2002). The density values were high and directly proportional to WB size.

Table 1. Comparison of hydration properties of wheat bran and other fibres.

\begin{tabular}{lcccc}
\hline \multicolumn{1}{c}{ Fibre } & WHC $(\mathrm{g} / \mathrm{g})$ & WRC $(\mathrm{g} / \mathrm{g})$ & SC $(\mathrm{mL} / \mathrm{g})$ & Reference \\
\hline Wheat bran & $\mathbf{3 . 3 9 - 6 . 4 9}$ & $\mathbf{2 . 1 7 - 5 . 7 6}$ & $\mathbf{3 . 5 0 - 7 . 6 7}$ & Present study \\
Rice bran total dietary fibre & 3.84 & 4.53 & 3.06 & Noort et al. (2010) \\
Coconut fibre & 6.00 & 3.30 & 20.00 & Raghavendra et al. (2004) \\
Wheat bran & $4.10-7.30$ & $2.90-5.90$ & $4.30-12.00$ & Jacobs et al. (2015) \\
Wheat bran & $3.45-5.89$ & $3.05-4.61$ & $4.65-5.79$ & Zhu et al. (2011) \\
Wheat bran & - & $2.10-6.50$ & $5.90-11.40$ & Hemdane et al. (2015) \\
\hline
\end{tabular}


The results for packed density in this study showed an inverse proportion with particle size. This is so because packed density is bulk density attained after mechanical tapping which leads to the compression of interspatial void between sample particles (Barbosa-Cánovas et al., 2005).

\subsection{Rheological properties}

\section{Effect of wheat bran on farinographic indices}

Mixing of wheat flour with water allows the activation of viscoelastic gluten network- which determines the quality of the final product (Hadnađev et al., 2011). Mechanical resistance of dough during mixing and kneading is measured by Farinograph. Farinograph result showed that water absorption (WA) of dough increased when WB in the flour increased from $1 \%$ to $15 \%$ (Table 3). Reducing particle size of WB from coarse to medium significantly $(\mathrm{p}<0.05)$ increased water absorption (from 66.03\% to $67.30 \%$ ) and later reduced to $65.87 \%$ with the addition of fine bran. Of all the parameters measured by Farinograph, water absorption is said to be the most practicable, because it helps to assess strength of flour (Hadnađev et al., 2011). It has been observed that fibres absorb significant amount of water in dough during mixing (Rosell et al., 2010; Miś et al., 2012). Dough development time (DT) significantly increased due to coarse bran supplementation of wheat dough, and later decreased in dough with medium and fine WB. Dough stability changed significantly $(\mathrm{p}<0.05)$ between the different bran particle sizes, and it decreased from 12.50 in control dough to 6.80 when concentration of bran was increased from $0-15 \mathrm{~g}$ in the dough. Mixing tolerance $(\mathrm{MTI})$ increased significantly $(\mathrm{p}<0.05)$ with

Table 2. Bulk and packed density of wheat bran.

\begin{tabular}{ccc}
\hline Wheat bran & ${ }^{\star}$ Bulk density $(\mathrm{g} / \mathrm{mL})$ & ${ }^{\star}$ Packed density $(\mathrm{g} / \mathrm{mL})$ \\
\hline Coarse & $0.17 \pm 0.01^{\mathrm{a}}$ & $0.21 \pm 0.01^{\mathrm{a}}$ \\
Medium & $0.26 \pm 0.00^{\mathrm{b}}$ & $0.31 \pm 0.00^{\mathrm{b}}$ \\
Fine & $0.32 \pm 0.01^{\mathrm{c}}$ & $0.42 \pm 0.03^{\mathrm{c}}$ \\
\hline
\end{tabular}

${ }^{*}$ Means with different superscript down the column are significantly different $(\mathrm{p}<0.05)$

using Duncan multiple comparison test. Values are means \pm standard deviation $(n=3)$. the reduction of particle size of bran, and increased with increases in the amount of WB added.

Fibres are known to bind water through capillary forces or direct absorption, and a reduction in particle size of WB has been shown to reduce water-binding capacity of the fibres (Noort et al., 2010). During mixing and kneading, WB is exposed to hygroscopic forces by different flour components which allow WB to pick up water molecules, and this is strongly bound to WB through formation of hydrogen bond. This bond is quite stronger than the bond formed when WB is hydrated. A gradual increase in farinograph WA of dough supplemented with $150 \mu \mathrm{m}$ WB from 10 to $40 \%$ has been reported (Sudha et al., 2007). Earlier studies have shown that increase in water absorption is a function of increments in concentration of WB supplemented in dough; while particle size of WB has little or no effect on farinograph WA (Zhang \& Moore, 1999; Sudha et al., 2007; Noort et al., 2010; Jacobs et al., 2015). There was an increase in WA, and dough stability when particle size diminished from $750 \mu \mathrm{m}$ to $50 \mu \mathrm{m}$, while a direct proportion was noticed between DT and particle size reduction in WB (Coda et al., 2014). Lower water absorption of 59-61.5\% in Sangak bread dough substituted with hydrothermaled bran was earlier reported (Mosharraf et al., 2009). This variation in water absorption is mainly caused by water interaction through hydrogen bonding with a higher number of hydroxyl groups which exist in fibre structure (Miś et al., 2012). Correlation of farinograph properties (Table 4) reveals a strong negative correlation (at 0.01 level) with a $\mathrm{r}^{2}$ value of 0.933 between dough stability and development for dough with medium WB.

This implies that increase in dough stability was accompanied by a decrease in development time. Simply put, the longer the dough's development time, the less stable the dough became. There is also a negative correlation $(\mathrm{p}<0.05)$ between WA and stability of fine, coarse WB dough as well as a combination of the three particle sizes. This means that an increase in water added to the dough, made the dough less stable. Development time for dough with medium WB (5.9-6.2 min) was significantly lower $(\mathrm{p}<0.05)$ than the control $(6.7 \mathrm{~min})$ probably due to increase in surface area of medium WB, while dough with coarse WB took longer time to develop (6.4 to $7.4 \mathrm{~min}$ ) as a result of the higher

Table 3. Comparison of means for Farinograph and Extensograph using Duncan's multiple range test.

\begin{tabular}{|c|c|c|c|c|c|c|c|}
\hline \multirow{2}{*}{ WB } & \multicolumn{4}{|c|}{ Farinogram } & \multicolumn{3}{|c|}{ Extensigram } \\
\hline & WA (\%) & $\mathrm{DT}(\min )$ & $\mathrm{S}(\mathrm{min})$ & MTI (FU) & Area $\left(\mathrm{cm}^{2}\right)$ & $\mathrm{R}_{\text {max }}(\mathrm{BU})$ & $\mathrm{E}(\mathrm{mm})$ \\
\hline CTRL & $61.90 \pm 0.1^{\mathrm{a}}$ & $6.70 \pm 0.1^{\mathrm{d}}$ & $12.50 \pm 0.03^{g}$ & $18.00 \pm 1.00^{\mathrm{a}}$ & $103.00 \pm 2.00^{\mathrm{e}}$ & $419.00 \pm 1.00^{j}$ & $180.00 \pm 2.65^{\circ}$ \\
\hline FWB1 & $64.60 \pm 0.20^{c}$ & $4.50 \pm 0.20^{\mathrm{a}}$ & $10.20 \pm 0.20^{\mathrm{f}}$ & $21.00 \pm 1.00^{\mathrm{b}}$ & $92.00 \pm 1.00^{\mathrm{d}}$ & $354.00 \pm 2.00^{\mathrm{h}}$ & $186.00 \pm 2.00^{\mathrm{i}}$ \\
\hline FWB8 & $65.60 \pm 0.30^{\mathrm{d}}$ & $6.30 \pm 0.30^{c}$ & $9.20 \pm 0.20^{\mathrm{d}}$ & $33.00 \pm 2.00^{\mathrm{d}}$ & $80.00 \pm 1.00^{c}$ & $348.00 \pm 2.00^{\mathrm{g}}$ & $165.00 \pm 2.00^{e}$ \\
\hline FWB15 & $67.40 \pm 0.40^{\mathrm{e}}$ & $7.20 \pm 0.10^{\mathrm{e}}$ & $8.60 \pm 0.10^{c}$ & $40.00 \pm 1.00^{\mathrm{e}}$ & $81.00 \pm 1.00^{c}$ & $333.00 \pm 2.00^{\mathrm{e}}$ & $172.00 \pm 1.00^{f}$ \\
\hline MWB1 & $64.10 \pm 0.10^{c}$ & $6.20 \pm 0.10^{\mathrm{bc}}$ & $9.70 \pm 0.20^{\mathrm{e}}$ & $27.00 \pm 1.00^{c}$ & $83.00 \pm 2.00^{c}$ & $343.00 \pm 2.00^{\mathrm{f}}$ & $172.00 \pm 1.00^{\mathrm{f}}$ \\
\hline MWB8 & $67.70 \pm 0.10^{\mathrm{e}}$ & $6.00 \pm 1.00^{\mathrm{b}}$ & $8.70 \pm 0.10^{c}$ & $28.00 \pm 2.00^{c}$ & $64.00 \pm 3.00^{\mathrm{b}}$ & $306.00 \pm 1.00^{\mathrm{d}}$ & $143.00 \pm 1.00^{\circ}$ \\
\hline MWB15 & $70.20 \pm 1.00^{\mathrm{g}}$ & $5.90 \pm 0.20^{\mathrm{b}}$ & $7.5 \pm 0.20^{\mathrm{b}}$ & $34.00 \pm 1.00^{\mathrm{d}}$ & $53.00 \pm 1.00^{\mathrm{a}}$ & $292.00 \pm 2.00^{\mathrm{b}}$ & $123.00 \pm 1.00^{\mathrm{a}}$ \\
\hline CWB1 & $63.00 \pm 1.00^{\mathrm{b}}$ & $7.00 \pm 1.00^{\mathrm{e}}$ & $12.70 \pm 0.20^{\mathrm{g}}$ & $21.00 \pm 1.00^{\mathrm{b}}$ & $101.00 \pm 1.00^{\mathrm{e}}$ & $402.00 \pm 2.00^{\mathrm{i}}$ & $183.00 \pm 2.00^{\mathrm{h}}$ \\
\hline CWB8 & $66.30 \pm 0.10^{\mathrm{d}}$ & $7.40 \pm 0.20^{\mathrm{ef}}$ & $8.70 \pm 0.20^{c}$ & $29.00 \pm 1.00^{c}$ & $64.00 \pm 3.00^{\mathrm{b}}$ & $296.00 \pm 1.00^{c}$ & $148.00 \pm 2.00$ \\
\hline CWB15 & $68.80 \pm 0.20^{\mathrm{f}}$ & $6.40 \pm 0.20^{c}$ & $6.80 \pm 0.20^{\mathrm{a}}$ & $27.00 \pm 0.10^{c}$ & $55.00 \pm 1.00^{\mathrm{a}}$ & $283.00 \pm 2.00^{\mathrm{a}}$ & $130.00 \pm 1.00^{\mathrm{b}}$ \\
\hline
\end{tabular}

Values are means \pm standard deviation $(\mathrm{n}=3)$. Means with different superscript in the columns are significantly different ( $\mathrm{p}<0.05)$. CTRL represents $100 \%$ wheat flour; FWB, MWB, and CWB represents fine, medium and coarse wheat bran particle sizes while 1, 8 and 15 represent \% wheat bran substitution in wheat flour. WA: water absorption; DT: development time; S: stability; MTI: mixing tolerance index. $\mathrm{R}_{\max }$ maximum resistance and E: extensibility. 
Table 4. Pearson's correlation of Farinograph indices.

\begin{tabular}{|c|c|c|c|c|}
\hline \multicolumn{2}{|c|}{ Farinograph indices } & WA (\%) & $\mathrm{DT}(\min )$ & $S(\min )$ \\
\hline \multirow{3}{*}{ Development Time (min) } & FWB & .195 & & \\
\hline & MWB & -.925 & & \\
\hline & CWB & -.206 & & \\
\hline \multirow{2}{*}{ Stability (min) } & FWB & $-.982^{\star}$ & -.092 & \\
\hline & MWB & -.949 & $-.993^{\star *}$ & \\
\hline \multirow{4}{*}{ Mixing tolerance Index (FU) } & FWB & .925 & .534 & -.891 \\
\hline & MWB & .929 & $-.965^{\star}$ & .987 \\
\hline & CWB & .878 & .286 & -.873 \\
\hline & $\mathrm{F}+\mathrm{M}+\mathrm{C}$ & $.701^{\star}$ & .267 & $-.689^{\star}$ \\
\hline
\end{tabular}

FWB: Measurements for dough with 3 fine bran additions plus 1 control; MWB: measurements for dough with 3 medium bran additions plus 1 control; CWB: measurements for dough with coarse bran additions plus 1 control $(\mathrm{n}=4) ; \mathrm{F}+\mathrm{M}+\mathrm{C}$ : measurements for dough, each with additions of 3 fine, 3 medium, 3 coarse bran and 1 control $(\mathrm{n}=10)$. ${ }^{\star}$ Correlation at the 0.05 level; ${ }^{* *}$ Correlation significance at the 0.01 level. WA: water absorption; DT: development time; S: stability.

WA of WB fibre due to its hydrophilic nature. The time it took to develop is increased because WB picks up water slowly and in turn delays development of the gluten network. Similar delayed DT in dough with rice bran has been observed (Ghufran et al., 2009). Stability of the dough is significantly reduced as the amount of WB in the dough increases. WB dilutes and/or competes with gluten in wheat flour for water uptake which results in weak dough which is less stable. This observation has been reported by other authors (Ghufran et al., 2009; Ashraf et al., 2012). Mixing tolerance index of WB increased significantly with increase in concentration of WB particle size. This increase was observed in a study where dough MTI increased from 25 to $70 \mathrm{BU}$ with an increasing amount of WB from 10 to $40 \%$ (Sudha et al., 2007).

\section{Effect of wheat bran addition on Extensograph parameters}

The area under the curve reduced from 92 to $53 \mathrm{~cm}^{2}$ with increase in $\mathrm{WB}$ concentration and particle size. There was no significant difference $(\mathrm{p}<0.05)$ in area values of control and dough with coarse WB. Lower values show that energy expended in stretching the dough to rupture point was low which indicated weaker dough. Lowest values were observed in the highest amounts of each particle size - showing that increasing addition of WB interferes with the gluten network, which in turn weakens the dough. There was a significant variation in the resistance to extension for all dough with respect to $\mathrm{WB}$ amounts and sizes. A contrary observation was reported in the study of Sudha et al. (2007) where resistance values increased with increasing addition of $\mathrm{WB}$, although the size was not taken into consideration in their study. Extensibility of dough with fine and coarse WB were significantly higher than the control, while there was a reduction in extensibility with increase in amounts of WB. Correlations of extensograph parameters show strong positive correlation $\left(\mathrm{r}^{2}=0.995\right)$ between maximum resistance and area under the curve for dough samples with coarse WB and a combination of the three particle sizes (Table 5).

This implies that an increase in coarse WB increased in the dough system, increased the resistance which in turn increased the area under the extension curve. There was a correlation
Table 5. Pearson's correlation of Extensograph parameters.

\begin{tabular}{|c|c|c|c|}
\hline \multicolumn{2}{|c|}{ Extensograph } & Area $\left(\mathrm{cm}^{2}\right)$ & $\mathrm{R}_{\max }(\mathrm{BU})$ \\
\hline \multirow{4}{*}{$\mathrm{R}_{\max }(\mathrm{BU})$} & FWB & .918 & \\
\hline & MWB & $.977^{\star}$ & \\
\hline & CWB & $.995^{\star *}$ & \\
\hline & $\mathrm{F}+\mathrm{M}+\mathrm{C}$ & $.965^{\star *}$ & \\
\hline \multirow{4}{*}{ Extensibility (mm) } & FWB & .730 & .400 \\
\hline & MWB & $.963^{*}$ & .883 \\
\hline & CWB & $.987^{\star}$ & $.966^{\star}$ \\
\hline & $\mathrm{F}+\mathrm{M}+\mathrm{C}$ & $.957^{\star *}$ & $.850^{* *}$ \\
\hline
\end{tabular}

FWB: Measurements for dough with 3 fine bran additions plus 1 control; MWB: measurements for dough with 3 medium bran additions plus 1 control; CWB: measurements for dough with coarse bran additions plus 1 control ( $n=4)$; $F+M+C$ : measurements for dough, each with additions of 3 fine, 3 medium, 3 coarse bran and 1 control $(\mathrm{n}=10)$. ${ }^{*}$ Correlation significance at the 0.05 level; ${ }^{* *}$ Correlation significance at the 0.01 level. $\mathrm{R}_{\text {max: }}$ maximum resistance.

(at 0.05 levels) between extensibility and area of the dough with fine and coarse WB, while a strong correlation (at 0.01 levels) was noticed for extensibility and resistance for the combination of the three sizes. This implies that maximum resistance and area for a combination of the three particle size will increase the extensibility of the dough.

\section{Relationship between farinograph and extensograph qualities}

The amount of WB added is the major factor which positively influenced the correlation of mixing and extensional properties reported in this study. Significant strong negative correlations existed between water absorption of dough and all extensograph parameters, except for fine bran amounts which had no significant relationship with extensibility of dough (Table 6). This implies that an increase in water absorption, coupled with increase in WB concentration, significantly reduced all extensograph indices of dough. The same observation in the linear correlation of extensograph and farinograph indices of dough enriched with carob and oatmeal fibre was reported in earlier studies (Miś et al., 2012). 
Table 6. Pearson's correlation for farinograph and extensograph indices.

\begin{tabular}{|c|c|c|c|c|c|}
\hline \multirow{2}{*}{$\begin{array}{l}\text { Extensograph } \\
\text { Indices }\end{array}$} & \multirow{2}{*}{ WB dose } & \multicolumn{4}{|c|}{ Farinograph indices } \\
\hline & & WA (\%) & $\mathrm{DT}(\min )$ & $\mathrm{S}(\mathrm{min})$ & MTI (FU) \\
\hline \multirow{3}{*}{ Area $\left(\mathrm{cm}^{2}\right)$} & FWB & -.930 & -.184 & $.971^{\star}$ & -.905 \\
\hline & MWB & $-.989^{*}$ & $.971^{\star}$ & $.982^{\star}$ & $-.956^{*}$ \\
\hline & $\mathrm{F}+\mathrm{M}+\mathrm{C}$ & $-.926^{\star *}$ & -.001 & $.931^{\star \star}$ & -.559 \\
\hline \multirow{2}{*}{$\mathrm{R}_{\max }(\mathrm{BU})$} & FWB & $-.957^{\star}$ & .088 & $.981^{\star}$ & -.793 \\
\hline & $\mathrm{F}+\mathrm{M}+\mathrm{C}$ & $-.905^{\star *}$ & .058 & $.958^{\star *}$ & -.594 \\
\hline \multirow{4}{*}{$\mathrm{E}(\mathrm{mm})$} & FWB & -.517 & -.622 & .562 & -.751 \\
\hline & MWB & $-.992^{\star \star}$ & .871 & .903 & -.885 \\
\hline & CWB & $-.981^{\star}$ & .223 & $1.000^{\star \star}$ & -.859 \\
\hline & $\mathrm{F}+\mathrm{M}+\mathrm{C}$ & $-.873^{\star *}$ & -.057 & $.817^{\star *}$ & -.431 \\
\hline
\end{tabular}

FWB: Measurements for dough with 3 fine bran additions plus 1 control; MWB: measurements for dough with 3 medium bran additions plus 1 control; CWB: measurements for dough with coarse bran additions plus 1 control $(n=4) ; F+M+C$ : measurements for dough, each with additions of 3 fine, 3 medium, 3 coarse bran and 1 control ( $\mathrm{n}=10) .{ }^{*} \mathrm{Correlation}$ significance at the 0.05 level; ${ }^{* *}$ Correlation significance at the 0.01 level. WA: water absorption; DT: dough development time; S: stability; MTI: mixing tolerance index; $\mathrm{R}_{\text {max }}$ : maximum resistance; E: extensibility.

Table 7. Effect of size reduction on colour profile of wheat bran.

\begin{tabular}{|c|c|c|c|}
\hline \multirow{2}{*}{ Colour properties } & \multicolumn{3}{|c|}{ Wheat bran } \\
\hline & Coarse & Medium & Fine \\
\hline $\mathrm{L}^{*}$ & $61.04 \pm 0.31^{\mathrm{a}}$ & $61.93 \pm 0.28^{\mathrm{b}}$ & $75.85 \pm 0.06^{c}$ \\
\hline$a^{*}$ & $8.5 \pm 0.13^{c}$ & $8.18 \pm 0.10^{\mathrm{b}}$ & $4.75 \pm 0.03^{\mathrm{a}}$ \\
\hline Hue & $64.25 \pm 0.23^{\mathrm{a}}$ & $68.47 \pm 0.18^{\mathrm{b}}$ & $74.63 \pm 0.10^{c}$ \\
\hline Chroma & $19.75 \pm 0.14^{\mathrm{b}}$ & $22.29 \pm 0.13^{c}$ & $17.92 \pm 0.02^{\mathrm{a}}$ \\
\hline
\end{tabular}

Means with different superscript across the row are significantly different $(\mathrm{p}<0.05)$ using Duncan multiple comparison test. Values are means \pm standard deviation $(\mathrm{n}=3)$. $\mathrm{L}^{*}=$ Lightness/darkness (100-0); $\mathrm{a}^{\star}\left(\right.$ red to green); $\mathrm{b}^{\star}$ (yellow to blue).

\subsection{Colour profile of wheat bran}

Size reduction had a significant $(\mathrm{p}<0.05)$ increasing effect on lightness and a decreasing effect on redness of WB. $\mathrm{L}^{*}, \mathrm{a}^{*}$, $\mathrm{b}^{*}$ values of WB which ranged from 61.04-75.85, 4.75-8.50, and 17.28-20.74, respectively (Table 7).

Fine WB was significantly lighter $(\mathrm{p}<0.05)$ than the other two particle sizes as indicated by the highest $\mathrm{L}$ value of 75.85 . This was also reflected in the whiteness index as fine WB had the highest degree of whiteness of 81.42 which can be linked to its floury nature as a result of the residual endosperm from inner pericarp found in the WB. Hue values increased significantly with reduction in size of WB. Higher hue angle has been known to represent less yellowness in a food product as evidenced in fine WB with the lowest $b^{*}$ value and simultaneously the highest hue angle of 74.63 (Pathare et al., 2013). Medium WB had the highest yellowness $\left(b^{*}\right)$ value of 20.74 as strengthened by an equivalent highest value of 47.83 for yellowness index which shows the degree of yellowness in $\mathrm{WB}$ as a result of processing by milling and sieving. Chroma quantifies the intensity of hue present in a product (Pathare et al., 2013). Chroma value of WB increased from 19.75 to 22.29 in medium WB and later reduced significantly to 17.92 in fine WB. Human's perception of colour intensity of a sample has been associated with higher chroma values (Pathare et al., 2013). Hence, medium WB can be said to have the highest colour intensity out of the three WB sizes. Effect of this colour intensity of medium bran in food will depend on the type of food and the amount added therein. Explicit colour profile on WB was not found in literature, but results similar to this study were reported in a study (Daou \& Zhang, 2011) where the $\mathrm{L} \mathrm{a}^{*} \mathrm{~b}^{*}$ values for insoluble and total dietary fibre of rice bran were not significantly different from each other but different from colour values of soluble dietary fibre.

\section{Conclusion}

Size reduction of WB from coarse particles to fine particles significantly decreased hydration properties while increasing lightness, redness and hue angle of WB. Size reduction to fine WB was characterized by highest lightness, hue and whiteness index values. Medium bran had the most intense colour in terms of yellowness. With the degree of whiteness in fine WB, its application of fine WB in food product might make such foods more appealing to consumers than coarse and medium wheat bran. Fine WB can be potentially used in greater amounts to enrich food products such as bread, doughnut, and cookies with less sensorial implications. Rheological properties of wheat dough were greatly influenced by the presence of WB and the 
extent of this influence was dependent on WB concentrations and less on WB particle size. Relationship between mixing and extensional properties showed both positive and negative correlations which can be used to explain the behaviour of wheat dough with various concentrations and sizes of WB, and in turn the various food products such as cookies, bread, doughnut to be developed from such dough. Utilization of the various WB sizes in foods products highlighted can potentially increase their fibre content. Medium and fine WB can be incorporated in products such as biscuit, rusks, bread, soups and yoghurt. Enriching these foods with medium and fine WB may reduce gritty taste that consumers associate with coarse WB-enriched products.

\section{References}

Ahmed, J., Almusallam, A. S., Al-Salman, F., Abdul-Rahman, M. H., \& Al-Salem, E. (2013). Rheological properties of water insoluble date fiber incorporated wheat flour dough. LWT - Food Science and Technology, 51(2), 409-416.

American Association of Cereal Chemists. (2000). Approved methods of the American Association of Cereal Chemists. St. Paul: AACC.

Ashraf, S., Saeed, S. M. G., Sayeed, S. A., Ali, R., Saeed, H., \& Ahmed, M. (2012). Effect of fat-replacement through rice milling by-products on the rheological and baking behaviour of dough. African Journal of Agricultural Research, 7(44), 5898-5904. http://dx.doi.org/10.5897/ AJAR12.1052.

Barbosa-Cánovas, G. V., Ortega-Rivas, E., Juliano, P., \& Yan, H. (2005). Bulk properties. In E. Ortega-Rivas, P. Juliano, \& H. Yan. Food powders: physical properties, processing, and functionality (pp. 5590). New York: Kluwer Academic.

Chesson, A., Gardner, P. T., \& Wood, T. J. (1997). Cell wall porosity and available surface area of wheat straw and wheat grain fractions. Journal of the Science of Food and Agriculture, 75(3), 289-295. http:// dx.doi.org/10.1002/(SICI)1097-0010(199711)75:3<289::AIDJSFA879>3.0.CO;2-R.

Coda, R., Kärki, I., Nordlund, E., Heiniö, R.-L., Poutanen, K., \& Katina, K. (2014). Influence of particle size on bioprocess induced changes on technological functionality of wheat bran. Food Microbiology, 37(2), 69-77. PMid:24230475. http://dx.doi.org/10.1016/j.fm.2013.05.011.

Daou, C., \& Zhang, H. (2011). Physico-chemical properties and antioxidant activities of dietary fiber derived from defatted rice bran. Advance Journal of Food Science and Technology, 5(3), 339-347.

Dobraszczyk, B. J., \& Morgenstern, M. P. (2003). Rheology and the breadmaking process. Journal of Cereal Science, 38(3), 229-245. http://dx.doi.org/10.1016/S0733-5210(03)00059-6.

Ghufran, S. M., Arif, S., Ahmed, M., Ali, R., \& Shih, F. (2009). Influence of rice bran on rheological properties of dough and in the new product development. Journal of Food Science and Technology, 46(1), 62-65.

Gómez, M., Jiménez, S., Ruiz, E., \& Oliete, B. (2011). Effect of extruded wheat bran on dough rheology and bread quality. LWT-. Food Science and Technology (Campinas.), 44(10), 2231-2237.

Hadnađev, T. D., Torbica, A., Pojić, M., \& Hadnađev, M. (2011). The role of empirical rheology in flour quality control. In I. Akyar (Ed.), Wide spectra of quality control (pp. 335-360). Rijeka: INTECH.

Hemdane, S., Jacobs, P. J., Dornez, E., Verspreet, J., Delcour, J. A., \& Courtin, C. M. (2016). Wheat (Triticum aestivum L.) bran in bread making: a critical review. Comprehensive Reviews in Food Science and Food Safety, 15(1), 28-42. http://dx.doi.org/10.1111/1541-4337.12176.

Hemdane, S., Leys, S., Jacobs, P. J., Dornez, E., Delcour, J. A., \& Courtin, C. M. (2015). Wheat milling by-products and their impact on bread making. Food Chemistry, 187(11), 280-289. PMid:25977028. http:// dx.doi.org/10.1016/j.foodchem.2015.04.048.

Jacobs, P. J., Hemdane, S., Dornez, E., Delcour, J. A., \& Courtin, C. M. (2015). Study of hydration properties of wheat bran as a function of particle size. Food Chemistry, 179(7), 296-304. PMid:25722168. http://dx.doi.org/10.1016/j.foodchem.2015.01.117.

Kock, S., Taylor, J., \& Taylor, J. R. N. (1999). Effect of heat treatment and particle size of different brans on loaf volume of brown bread. LWT-Food Science and Technology, 32(6), 349-356. http://dx.doi. org/10.1006/fstl.1999.0564.

Majzoobi, M., Farahnaky, A., Nematolahi, Z., Mohamadi Hashemi, M., \& Taghipour, M. (2012). Effect of different levels and particle sizes of wheat bran on the quality of flat bread. Journal of Agricultural Science and Technology, 15(1), 115-123.

Miś, A., Grundas, S., Dziki, D., \& Laskowski, J. (2012). Use of farinograph measurements for predicting extensograph traits of bread dough enriched with carob fibre and oat wholemeal. Journal of Food Engineering, 108(1), 1-12. http://dx.doi.org/10.1016/j. jfoodeng.2011.08.007.

Mosharraf, L., Kadivar, M., \& Shahedi, M. (2009). Effect of hydrothermaled bran on physicochemical, rheological and microstructural characteristics of Sangak bread. Journal of Cereal Science, 49(3), 398-404. http:// dx.doi.org/10.1016/j.jcs.2009.01.006.

Noort, M. W., van Haaster, D., Hemery, Y., Schols, H. A., \& Hamer, R. J. (2010). The effect of particle size of wheat bran fractions on bread quality: evidence for fibre-protein interactions. Journal of Cereal Science, 52(1), 59-64. http://dx.doi.org/10.1016/j.jcs.2010.03.003.

Onipe, O. O., Jideani, A. I., \& Beswa, D. (2015). Composition and functionality of wheat bran and its application in some cereal food products. International Journal of Food Science \& Technology, 50(12), 2509-2518. http://dx.doi.org/10.1111/ijfs.12935.

Pathare, P. B., Opara, U. L., \& Al-Said, F. A. J. (2013). Colour measurement and analysis in fresh and processed foods: a review. Food and Bioprocess Technology, 6(1), 36-60. http://dx.doi.org/10.1007/ s11947-012-0867-9.

Prakash, J. (2002). Wheat bran (Triticum aestivum): composition, functionality and incorporation in unleavened bread. Journal of Food Quality,25(3), 197-211. http://dx.doi.org/10.1111/j.1745-4557.2002. tb01019.x

Prakongpan, T., Nitithamyong, A., \& Luangpituksa, P. (2002). Extraction and application of dietary fiber and cellulose from pineapple cores. Journal of Food Science, 67(4), 1308-1313. http://dx.doi. org/10.1111/j.1365-2621.2002.tb10279.x.

Raghavendra, S. N., Rastogi, N. K., Raghavarao, K. S. M. S., \& Tharanathan, R. N. (2004). Dietary fiber from coconut residue: effects of different treatments and particle size on the hydration properties. European Food Research and Technology, 218(6), 563-567. http://dx.doi. org/10.1007/s00217-004-0889-2.

Rosell, C. M., Santos, E., \& Collar, C. (2010). Physical characterization of fiber-enriched bread doughs by dual mixing and temperature constraint using the Mixolab ${ }^{\star}$. European Food Research and Technology, 231(4), 535-544. http://dx.doi.org/10.1007/s00217-010-1310-y.

Sobota, A., Rzedzicki, Z., Zarzycki, P., \& Kuzawińska, E. (2015). Application of common wheat bran for the industrial production of high-fibre pasta. International Journal of Food Science \& Technology, 50(1), 111-119. http://dx.doi.org/10.1111/ijfs.12641.

Song, X., Zhu, W., Pei, Y., Ai, Z., \& Chen, J. (2013). Effects of wheat bran with different colors on the qualities of dry noodles. Journal of Cereal Science, 58(3), 400-407. http://dx.doi.org/10.1016/j.jcs.2013.08.005. 
Sudha, M. L., Vetrimani, R., \& Leelavathi, K. (2007). Influence of fibre from different cereals on the rheological characteristics of wheat flour dough and on biscuit quality. Food Chemistry, 100(4), 13651370. http://dx.doi.org/10.1016/j.foodchem.2005.12.013.

Wang, J., Rosell, C. M., \& Barber, C. B. (2002). Effect of the addition of different fibres on wheat dough performance and bread quality. Food Chemistry, 79(2), 221-226. http://dx.doi.org/10.1016/S03088146(02)00135-8.

Yadav, D. N., \& Rajan, A. (2012). Fibres as an additive for oil reduction in deep fat fried poori. Journal of Food Science and Technology, 49(6), 767-773. PMid:24293697. http://dx.doi.org/10.1007/s13197010-0218-7.
Zaidel, D. A., Chin, N. L., \& Yusof, Y. A. (2010). A review on rheological properties and measurements of dough and gluten. Journal of Applied Sciences, 10(20), 2478-2490. http://dx.doi.org/10.3923/ jas.2010.2478.2490

Zhang, D., \& Moore, W. R. (1999). Wheat bran particle size effects on bread baking performance and quality. Journal of the Science of Food and Agriculture, 79(6), 805-809. http://dx.doi.org/10.1002/ (SICI)1097-0010(19990501)79:6<805::AID-JSFA285>3.0.CO;2-E.

Zhu, K.-X., Lian, C.-X., Guo, X.-N., Peng, W., \& Zhou, H.-M. (2011). Antioxidant activities and total phenolic contents of various extracts from defatted wheat germ. Food Chemistry, 126(3), 1122-1126. http://dx.doi.org/10.1016/j.foodchem.2010.11.144. 